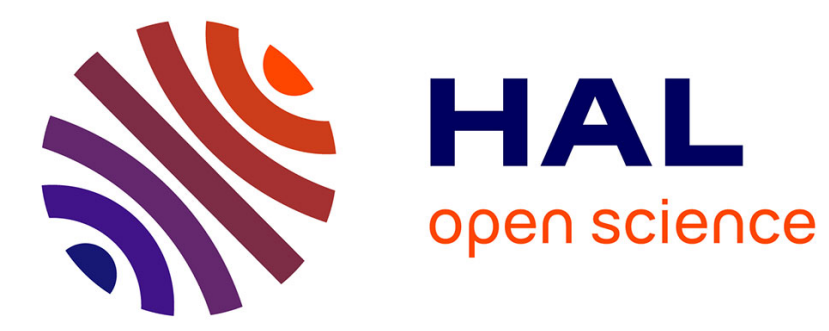

\title{
Diagnostic tools for PEMFCs: from conception to implementation
}

\author{
Catherine Cadet, Samir Jemei, Florence Druart, Hissel Daniel
}

\section{To cite this version:}

Catherine Cadet, Samir Jemei, Florence Druart, Hissel Daniel. Diagnostic tools for PEMFCs: from conception to implementation. International Journal of Hydrogen Energy, 2014, 39 (20), pp.1061310626. 10.1016/j.ijhydene.2014.04.163 . hal-01008777

\section{HAL Id: hal-01008777 https://hal.science/hal-01008777}

Submitted on 6 Oct 2021

HAL is a multi-disciplinary open access archive for the deposit and dissemination of scientific research documents, whether they are published or not. The documents may come from teaching and research institutions in France or abroad, or from public or private research centers.
L'archive ouverte pluridisciplinaire HAL, est destinée au dépôt et à la diffusion de documents scientifiques de niveau recherche, publiés ou non, émanant des établissements d'enseignement et de recherche français ou étrangers, des laboratoires publics ou privés. 


\title{
Diagnostic tools for PEMFCs: from conception to implementation
}

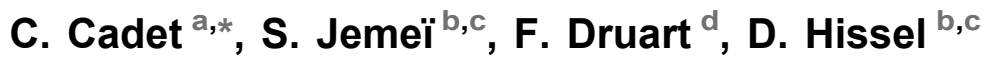 \\ ${ }^{a}$ GIPSA-LAB (UMR 5216 CNRS, Grenoble-INP eUJF-Stendhal Univ.), 11 rue des Mathématiques, BP 46, 38402 Saint Martin d'Hères Cedex, France \\ ${ }^{\mathrm{b}}$ FCLAB Research Federation, FR CNRS 3539, rue Thierry Mieg, 90010 Belfort Cedex, France \\ ' University of Franche-Comte', FEMTO-ST (UMR CNRS 6174), rue Thierry Mieg, 90010 Belfort Cedex, France \\ 'LEPMI (UMR 5279 CNRS, Grenoble-INP eUJF eUniv. de Savoie), BP75, 38402 Saint Martin d'Hères Cedex, France
}

\section{Introduction}

Fuel cells convert the reactant's chemical energy directly into electrical and thermal energy with high efficiency and good environmental compatibility. In particular, the Polymer Electrolyte Membrane Fuel Cell (PEMFC) technology is appropriate for small-scale power generation applications [10 W-100 kW] - including transportation and household applications - because of its low operating temperature range $\left(60-80^{\circ} \mathrm{C}\right)$. To be competitive, Fuel Cells must be able to match or outperform conventional devices in cost, durability, performance and reliability. These aspects can be greatly improved by optimising operating conditions, which prevent irreversible damages to the fuel cell. To reach this goal, operation of fuel cells has to be managed by advanced methods of supervision, and more generally by Prognostics and Health Management (PHM). PHM is a new area of science that proposes methods to:

- Assess the State of Health of a Fuel Cell (State of Health $\mathrm{SoH})$,

\footnotetext{
* Corresponding author. Tel.: +334 768264 12; fax: +334 76826388.

E-mail addresses: catherine.cadet@gipsa-lab.grenoble-inp.fr (C. Cadet), samir.jemei@univ-fcomte.fr (S. Jemeï), florence.druart@ lepmi.grenoble-inp.fr (F. Druart), daniel.hissel@univ-fcomte.fr (D. Hissel).

http://dx.doi.org/10.1016/j.ijhydene.2014.04.163.
} 
- Predict its Remaining Useful Life (RUL),

- Decide from mitigation/control actions for mission achievement.

In a Prognostic and Health Management (PHM) approach, monitoring data collected during normal operations are used during maintenance. This approach is based on The State of Health diagnosis, which identifies and isolates different faults that may accelerate the ageing process of the fuel cell stack during normal operations. In that sense, faults such as flooding, drying and $\mathrm{CO}$ poisoning are considered during $\mathrm{SoH}$ diagnosis. The Prognostic goes further by predicting the Remaining Useful Life. Then, various recommendations, maintenance actions or corrective actions on the control system can be made. The accuracy of the results of the PHM approach is closely linked to $\mathrm{SoH}$ diagnosis.

$\mathrm{SoH}$ diagnosis aims at determining the cause of the problems that will lead to durability reduction. Developing a diagnostic tool includes several stages, beginning with data acquisition and progressing to data treatment, fault detection and classification. In the data acquisition stage, instrumentation must be as non-intrusive as possible. Active data acquisition, which requires the generation of an excitation signal (e.g., Electrochemical Impedance Spectrometry - EIS), can also be distinguished from non-active methods that do not require specific tests. Data treatment aims at extracting and selecting features that enable characterising the behaviour of the Fuel Cells. Numerous techniques have been used, such as EIS [1-12], temporal approaches [13-28] and timefrequencies [29-32]. A review of these methods for water management is available in Ref. [33]. At this stage, measurements are organised in features characterising defaults and form the reference database.

Fault detection and classification are the search techniques that transform the database to make the final diagnosis decision. Fault detection compares on-line data with expected values to detect abnormal behaviour. Two main approaches have been developed. The first is the model-based method of fault detection, which uses dynamic process models. The model may be based on theoretical analytical relationships but also on neural networks, fuzzy logic [34] or statistical methods [34-38]. Model-based methods rely on parameter estimation, parity equations or state observers [39]. The second class is signal-based approaches, which were also developed in Refs. [29-32,40]. Their main advantage is their high robustness whenever considering different types of fuel cell stacks. Regardless of the approach, the goal is to generate several residuals indicating the difference between nominal and faulty statuses. Based on these different residuals, fault diagnosis procedures follow, determining the cause of the fault by applying classification or inference methods [41]. Classification aims to automatically interpret the detection results and to suggest fault cases.

Previous studies devoted to diagnostic methodology comparison are very scarce. Cooper and Smith [42] compared several methods of data acquisition and treatment: current interrupt, High Frequency Resistance (HFR) and Electrochemical Impedance Spectroscopy (EIS). The estimated ohmic resistances differ from 10 to $30 \%$ according to the method used, which exceeds that which is reasonably accounted for by measurement error. Petrone et al. [34] reviewed modelbased methodologies for PEMFCs. The comparisons focus on the advantages and drawbacks of the type of model (whitebox, grey box and black-box) to aid in developing a suitable diagnostic tool. These studies compare the methods themselves and do not use external standards to establish the best method for operational readiness. The development of a diagnostic tool will only be completed after making sure that the tool is operational. These standards would aim to determine:

- Diagnostic performances: validation of the results obtained by the classification algorithm must be performed;

- Genericness, repeatability and reproducibility: the diagnostic tool should detect faults for all stacks and not only the one used for the tool design. This is a highly complex and challenging task without which the diagnostic tool is not operational. Repeatability and reproducibility of diagnostic results rely essentially on the database representativeness, which is a challenge partly due to the large variety of stacks coming from different suppliers (with different sizes, power levels and materials). Genericness requires a precise definition of defaults, and even default quantification when it is possible.

Once the diagnostic tool is tuned, implementation must be economically worthwhile. Thus, for mass production, instrumentation must be inexpensive and the testing phases dedicated to diagnosis must not require too much energy or time consumption.

With these goals in mind, all of the stages involved in the design of diagnostic tools shall be reviewed to find out how to establish standards. This paper suggests appropriate solutions to today's state-of-the-art diagnostic tools of fuel cells.

Section 2 below introduces the different fault diagnostic approaches, highlighting the link between dataset and computational methods. Section 3 presents the proposed approach, which is separated into three subsections: the first addresses reference database generation, the second with evaluation of fault detection and classification performances and the third with implementation aspects. Section 4 illustrates the approach on an example of a diagnostic study [38].

This paper does not pretend to be a review but aims to rationalise and reinterpret previously published results concerning fuel cell diagnosis areas. The topic is intentionally limited to water management (drying and flooding). However, generalisation is straightforward.

\section{An overview of fault diagnosis approaches}

\section{Features of flooded and dried fuel cells}

A fuel cell is composed of many single cells that are grouped together to form a fuel cell stack. Each single cell contains an anode, a cathode and an electrolyte layer (a polymer membrane when considering PEM fuel cells). The stack is fed by reactive gases (hydrogen and oxygen or air) through bipolar plates containing channels. When a hydrogen-rich fuel enters the fuel cell stack, it reacts electrochemically with oxygen 
(mostly coming from ambient air) to produce electricity, heat and water. Hydrogen fuel is processed at the anode where electrons are separated from protons on the surface of a platinum-based catalyst. The protons pass through the membrane to the cathode side of the cell while the electrons travel in an external circuit. Protons are able to cross the membrane only if attached to water molecules. On the cathode side, another precious metal electrode combines the protons and electrons with oxygen to produce water, which is expelled as the only waste product. The stack is considered as flooded when liquid water blocks the flow channels and/or the pores of the Gas Diffusion Electrodes (GDE), reducing the catalyst active sites, and thus leading to voltage drop. The dehydration state of the membrane (called also "drying") will limit proton migration from the anode to the cathode side, leading equally to a voltage drop. Flooding and drying are important limiting factors of PEM fuel cell performance. Water management is thus essential to ensure proper operation of the PEM fuel cells. More details on voltage degradation associated with water management can be found in Ref. [33].

The polarisation curve characterises fuel cell static performances. Fig. 1 shows fuel cell polarisation curves that were recorded on a $150 \mathrm{~cm}^{2}$ six-cell air/ $\mathrm{H}_{2}$ PEM fuel cell [2]. The fuel cell was operating under nominal, flooded and dried conditions obtained by modifying the inlet gas relative humidity. Fig. 1 shows that for currents above $200 \mathrm{~mA} \mathrm{~cm}^{-2}$, a faulty fuel cell operates at a significantly lower voltage than a healthy one. However, it seems almost impossible to tell which of the two failures caused the voltage drop: for a given current, excessive drying or flooding of the fuel cell can lead to the same voltage, as seen here in Fig. 1, where the "flooded" and "dry" polarisation curves are almost superimposed.

Methods based on polarisation curve allow for the detection of faults but have significant limitations for diagnostic purposes. Indeed, on one hand, a quasi-steady state experiment is needed, which is an important constraint; on the other hand, isolating the cause of the fault is not always possible.

Electrochemical Impedance Spectroscopy (EIS) is a noninvasive method that consists of applying a small alternative

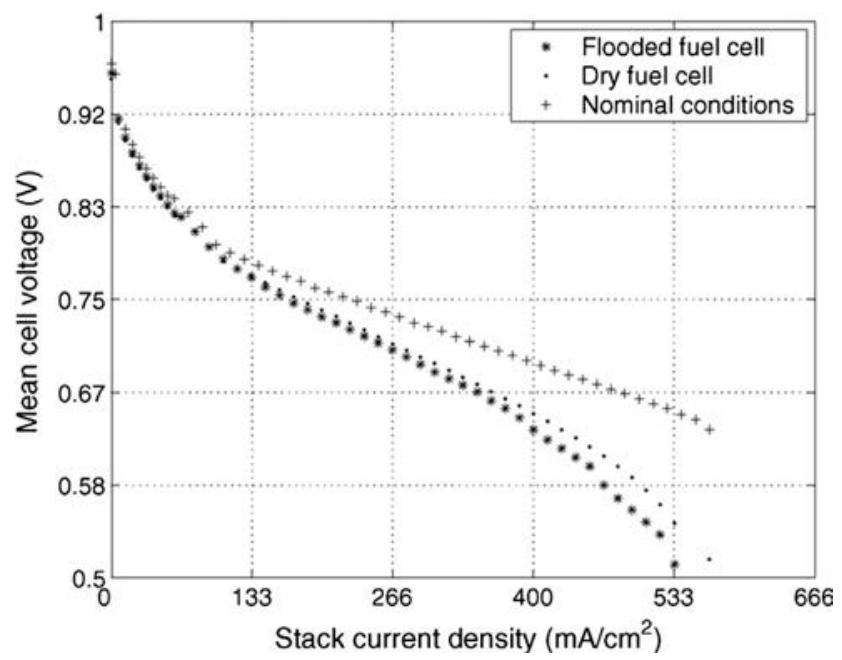

Fig. 1 - Measured polarisation curves for a stack operating under flooded, dried and nominal conditions [2].

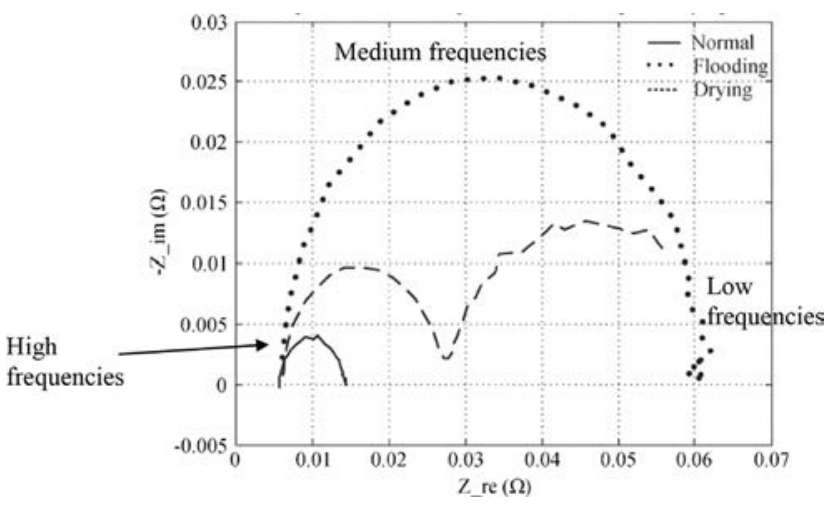

Fig. 2 - Impedance response of a normal, flooded, and dried cell [4].

perturbation, for which the amplitude, phase and frequency are known. For the full impedance spectrum, the disturbance must be repeated at different frequencies. A comparison of the impedance response for a normal, flooded and dried cell is shown in Fig. 2 [4]. The experimentation has been carried out on a $10 \mathrm{~cm}^{2}$ single cell. To ensure consistency and repeatability of the experiments, operating parameters are kept constant (gas flows, pressure, humidity, cell current). To create flooding in the cell, the humidifier temperature was maintained at approximately $40{ }^{\circ} \mathrm{C}$ or higher than the cell temperature, whereas the cell temperature was then maintained at approximately $40^{\circ} \mathrm{C}$ or higher than the humidifier to create drying. Frequencies ranging from $0.1 \mathrm{~Hz}$ to $1 \mathrm{kHz}$, with 10 measurement points per decade, were used for all of these spectra. Inductive behaviour from the wires was predominant above $1 \mathrm{kHz}$, while instability of the system led to highly irreproducible results below $0.1 \mathrm{~Hz}$. The impedance spectrum of the normal and flooding states contains 1 semicircle, which corresponds to the cathode side, anode impedance being negligible. During the flooding process, both the real and imaginary parts of the cell impedance increase as the liquid water accumulation in the cathode side increases. However, the shape (semicircle) of the impedance response remains almost the same, with the exception of increased diameter and a slight shift to the right. The drying state therefore contains 2 semicircles, showing an increase of the impedance at the anode side, which makes it different from the flooding fault. Thus, unlike polarisation curves, each impedance spectrum exhibits its specific shape or feature with respect to flooding or drying of the fuel cell $[1,8]$.

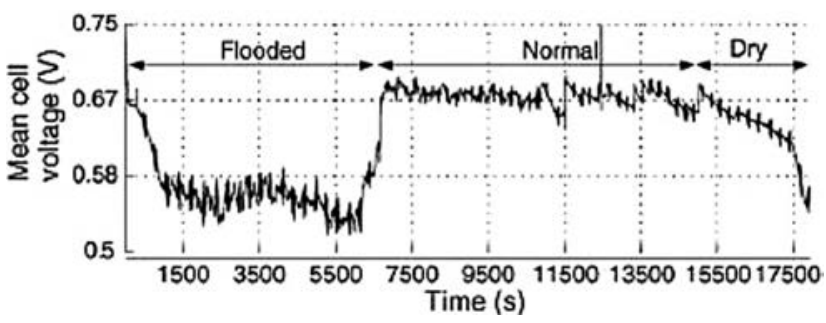

Fig. 3 - Mean cell voltage of a fuel cell in flooded, normal and dried conditions [2]. 
Fig. 3 shows the mean cell voltage of a $150 \mathrm{~cm}^{2}$ six-cell air/ $\mathrm{H}_{2}$ stack during a 5-h experiment, during which the stack was successively operated in flooded, nominal and dried conditions [2]. The DC current was kept constant for the duration of the test, to ensure that the State of Health $(\mathrm{SoH})$ of the fuel cell is solely responsible for the voltage variation. As seen in Fig. 3, there are no obvious methods of diagnosing the State of Health of the stack from its voltage. For a given current, flooded and dried conditions can lead to the same voltage drop [2]. However, some recent studies do not use exactly the voltage, but the electrochemical noise voltage. There are timefrequency methods, such as Power Spectral Densities (PSD) $[30,31]$ or FFT [29], or even wavelets [32], that are considered as very promising for real-time diagnosis of fuel cell stacks.

An alternative is to use the variations of the current in operation (Fig. 4) [13,15]. Dynamics are then assumed to be sufficient to extract data on the hydration state of the stack. Diagnosis methods can also generate their own dynamics on the stack, such as current interruption [23] or current steps [19]. In these instances, the flooding or drying state of the fuel cell cannot be directly characterised, and processing of the data is necessary.

\section{Consequences on diagnostic methods}

Fault detection is based on the fact that "normal state", "flooding state" and "drying state" show specific features, which constitute the reference database. This reference database is compared with the data to be tested. Feature extraction may consist of estimating a distance between the data to be tested and the reference curve of each state. Another approach is to establish one or more models reproducing the observed behaviour. Features to be extracted are then the model parameters, which are estimated. Classification can then be performed based either on estimated or parameter distances. Expanding the method to other faults, such as CO poisoning, is based on the search for new specific features based on EIS or polarisation curves [5,7,10]. Adding new measurements [20], proposes to also use pressure oscillations in addition to voltage oscillations. EIS methods may also be extended to maintenance strategies [44] or estimation of ageing time [45].

Diagnostic methods using mean voltage must use an additional source of information, for which pressure drop may be a useful selection $[14,29]$. Fault detection using several types of measurements is based on residual thresholds: the difference between the measurements and the reference database is compared with a threshold. Expansion of the method to include fault sensing or process failures, which are detectable by other specific measurements, is thus straightforward. This approach is therefore suitable for use in a faulttolerant control structure. Approaches using noise measurements lead to time-frequency signal-based approaches, such as Power Spectral Density or wavelets, which are under development, and their appeal will lie in their ability to handle both water management and ageing problems.

Diagnostic methods based on a time voltage signal allow for taking into account the different operating phases (starting, transient, steady-state). The challenge is to detect defaults during very short transient periods. Diagnostic methods may then be based on a model, which can be established on various concepts [34], such as statistics, fuzzy logic or knowledge of the physical or electrical phenomena. The advantage is that model-based methods are ready to be used by the control strategy [39]. The efficiency of these methods is completely dependent on the relevance and reliability of
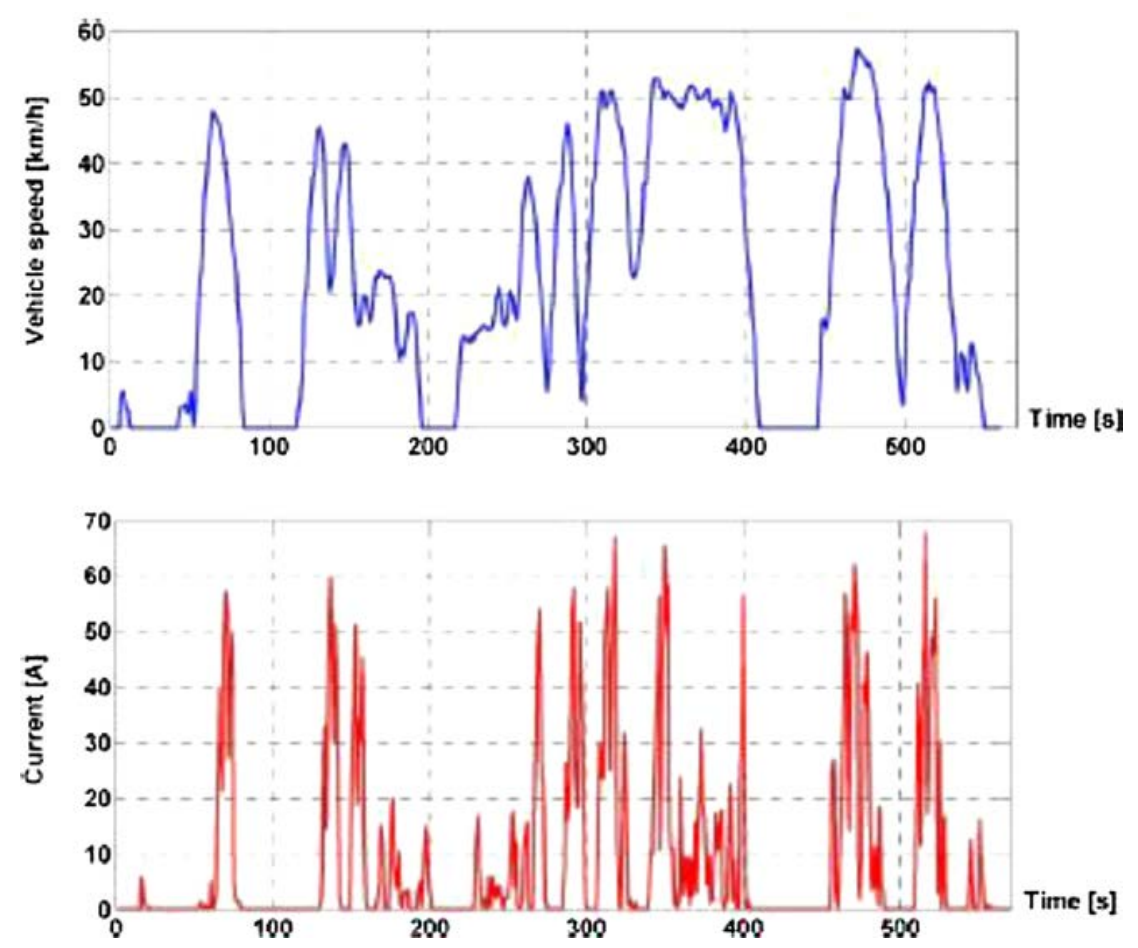

Fig. 4 - Evolution of the current demand (derived from the vehicle real speed) [43]. 
established models. In addition, the extension of this approach to ageing is linked to the development of dynamic models of ageing, which are currently underdeveloped.

\section{Proposed approach}

Collecting data is the first step when developing a diagnosis method. Taking care of the way data are collected is very important because accuracy and reliability of diagnostic tools are closely linked to the quality of the database. However, it is equally the most difficult point. For that reason, this section deals first with the ways to generate a representative database.

\section{Fault database relevance criteria}

Repeatability of experiments is a classical challenge: the same experiments led on different fuel cells or test benches yield different results. This is why it is believed that only a single database would allow for the comparison of methods, but then genericness of the diagnostic tool would be lost. Here, the opposite idea is explored: criteria allowing for the comparison of experiments are proposed.

\section{Test range of the stack}

Checking the variation range of the operating parameters used for the tests is easy to establish. In addition, it provides a basis for comparing database representativeness. Two criteria on the operating parameters are proposed: the experimental relative variations with respect to the operating point, and the rate of experimental range on the manufacturing range.

The relative variations of the manipulated parameters with respect to the operating point can always be estimated. The influencing parameters are current density (j), stack temperature $(T)$, anode overstoichiometry $\left(\lambda_{\mathrm{a}}\right)$, cathode overstoichiometry $(\lambda c)$ and relative humidity at anode and cathode $(\Phi)$ and pressure $(P)$. Their relative variations are then:

$\left.\frac{\Delta x}{x}\right|_{\min , \operatorname{Exp}}=\frac{x_{\min , \operatorname{Exp}}-x_{\text {ref }}}{x_{\text {ref }}}$

$\left.\frac{\Delta x}{x}\right|_{\max , \operatorname{Exp}}=\frac{x_{\text {max }, \operatorname{Exp}}-x_{\text {ref }}}{x_{\text {ref }}}$

where $x$ is one of the parameters $\left[j, T, \lambda_{a}, \lambda_{c}, \Phi, P\right], x_{\text {ref }}$ is the reference value at the operating point, $x_{\min , \operatorname{Exp}}$ is the minimal value taken in the whole experiment and $x_{\max , \operatorname{Exp}}$ is the maximal value taken in the whole experiment.

The manufacturer of a fuel cell also gives the operating range of the parameters, thus another criteria may be estimated. The rate of the experimental range on the manufacturing one is:

$\frac{\Delta x_{\operatorname{Exp}}}{\Delta x_{\text {Man }}}=\frac{x_{\text {max }, \text { Exp }}-x_{\min , \operatorname{Exp}}}{x_{\text {max }, \text { Man }}-x_{\min , \text { Man }}}$

where $x_{\min , \text { Man }}$ is the minimal value given by the manufacturer and $x_{\max , \text { Man }}$ is the maximal value.

Ideally, this ratio should be equal to one, but this is never the case. The reason is that all combinations of the parameter values are not necessarily achievable or are avoided: they may lead to an instability of the stack's behaviour or to premature ageing of the stack. Stack durability may be affected by low amplitudes of the excitation signal (when establishing a polarisation curve or impedance spectroscopy spectrum) or by rougher solicitations (such as a current step, for example). As far as we know, there is no method for anticipating the effect of a combination of parameter values on the stack. Only M.A. Riascos and D.D. Peireira [48] suggested an empirical equation on temperature limitations with respect to other operating parameters. This is an important research area that should be developed.

One consequence is that the ranges of the operating parameters effectively used are known only after experimentation. Thus, establishing the database by means of experimental designs [49], which scan all the available ranges of parameters, is not suitable, and so this method is progressively set aside. In order to perform a correct experimentation, the operating parameter values have to be increased according to a small step defined by the user. The important thing is to create flooding and drying defaults. However, if the previous criteria are easy to establish, quantifying the degrees of these defaults is more difficult.

\section{Evaluation of the degrees of flooding and drying}

Flooding and drying conditions are continuously varying degrees of humidity in the stack and are the results of two opposite mechanisms: water formation and water extraction. Water balance depends on [50]: (i) the water carried inside and outside the fuel cell by the humidified reactant gases, (ii) the water generated by the electrochemical reaction at the cathode, (iii) the water carried by the protons that are transported through the membrane (electro-osmotic drag) and (iv) the water carried by diffusion caused by water gradient concentration (often occurring from cathode to anode, called backdiffusion). The net amount of water transported across the membrane is the result of the last two processes directed in opposite directions.

Improper water management can lead to membrane dehydration caused by anode side drying or electrode flooding. Dehydration of the membrane is more likely to occur at high stoichiometry and high temperature. The general consensus is that water flooding is more prone to occur at the cathode than at the anode. Flooding occurs not only in the porous electrodes themselves but in the gas flow channels of the flow field as well, depending on the interplay between the properties and the engineering of those components and the operating conditions. More details can be found in Ref. [50]. These mechanisms are influenced directly by each operating condition [51].

Table 1 shows the influence that the modification from the optimal point of a single parameter has on the accumulation or the discharge of the water. To create flooding or drying defaults, only one parameter can be changed, such as, for example, increasing or decreasing the relative humidity at the cathode. This is a simple way to establish the database and ensures the progressiveness of the degrees of flooding or drying. However, these experiments are most likely not truly representative of normal operating conditions.

In Table 1, each operating parameter is supposed to be changed one by one, but they are in fact deeply correlated, and 
Table 1 - Independent influence of operating parameters in water content in the fuel cell.

\begin{tabular}{lccccccc} 
Water & $j$ & $T$ & $\lambda_{\mathrm{a}}$ & $\lambda_{\mathrm{c}}$ & $\Phi_{\mathrm{a}}$ & $\Phi_{\mathrm{c}}$ & $P_{\mathrm{a}}$ \\
content & & & & & & & \\
\hline Increase & $\uparrow$ & $\downarrow$ & $\downarrow$ & $\downarrow$ & $\uparrow$ & $\uparrow$ & $\uparrow$ \\
Decrease & $\downarrow$ & $\uparrow$ & $\uparrow$ & $\uparrow$ & $\downarrow$ & $\downarrow$ & $\downarrow$ \\
\hline
\end{tabular}

$j$ is the current density, $T$ is the stack temperature, $\lambda_{a}$ is the anode overstoichiometry, $\lambda \mathrm{c}$ is the cathode overstoichiometry, $\Phi$ is the relative humidity and $P$ is the pressure (a: at anode side, $c$ : at cathode side).

$\uparrow$ upper optimal point, $\downarrow$ lower optimal point.

a change in one operating parameter may affect others. Equations (4)-(6) below highlight the interactions between the parameters. Current density (j) directly generates water by the electrochemical reaction at the cathode. It should also be noticed that the cathode supplied with air, rather than with pure oxygen, will encourage the rate of water removal. Temperature $(T)$ influences the kinetics of the electrochemical half-reactions and, therefore, a high temperature induces the formation of water during the reduction of oxygen at the cathode. They are linked by the Butler-Volmer equation:

$j=j_{0}\left[\exp \left((1-\alpha) \frac{n F \eta}{R T}\right)-\exp \left(-\alpha \frac{n F \eta}{R T}\right)\right]$

where $j_{0}$ is the exchange current density $\left(\mathrm{A} / \mathrm{m}^{2}\right), \alpha$ the charge transfer coefficient, $n$ the number of electrons involved in the electrode reaction, $F$ the Faraday's constant (96484C/eq.), $\eta$ the activation overpotential, $R$ the universal gas constant $(8.3144 \mathrm{~J} /$ $\mathrm{Kmol}$ ) and $\mathrm{T}$ the absolute temperature $(\mathrm{K})$.

However, the saturation pressure of the gas increases severely with temperature, and a low temperature will facilitate the formation of water by condensation. The expression below describes the effect of temperature on saturation pressure:

$P_{\text {sat }}=\exp \left(23.1961-\frac{3816.44}{T-46.13}\right)$

Raising the pressure increases the stack performance (higher current for the same power). It also affects the presence of water; a high pressure will induce condensation of the water that occurs when:

$P_{\mathrm{w}}>P_{\text {sat }}$

where $P_{\mathrm{w}}$ is the partial pressure of water.

These equations show that choosing operating parameters to create the defaults is not an easy task. Establishing a quantitative criterion of default degrees of flooding and drying should thus be extremely useful. The judicious use of very simple laws and balance equations may help in estimating slight increases or decreases in the amount of water. Models based on static macroscopic balances were developed to estimate the amount of water in the membrane $[25,40]$. These models aim to handle water management by control strategies and need to be validated. An interesting point would be to determine, before experimentation, which parts of the stack, such as electrodes or channels, are affected.
However, with very simple relations, water flows can be approximated using only a few parameters [52]: stack voltage, current, the number of electrons involved in the electrode reaction and air stoichiometry. Thus, considering the homogeneous concentrations in the fuel cell, the partial water balance at the cathode can be written as:

$F_{\mathrm{w}}^{\text {in }}-F_{\mathrm{w}}^{\text {out }}-\alpha_{\mathrm{w}} F_{\text {prod }}+F_{\text {prod }}=0$

$\alpha_{\mathrm{w}}=\frac{\text { transfered water }_{\mathrm{C} \rightarrow \mathrm{A}}}{\text { produced water }}$

where $F_{\mathrm{w}}^{\mathrm{in}}$ is the water flow input, $F_{\mathrm{w}}^{\text {out }}$ the water flow output, $F_{\text {prod }}$ the water flow produced at the cathode and $\alpha_{\mathrm{W}}$ the partition coefficient of water produced at the cathode that is transferred to the anode.

The variation of overstoichiometry coefficients $(\lambda)$ impacts the mass balance in the stack. Indeed, a strong flow of dry gas (high stoichiometry) encourages the dragging of water out of the fuel cell, which will change the partition coefficient $\alpha_{\mathrm{w}}$. Thus, $F_{\mathrm{w}}^{\text {out }}$ can be deduced from Equation (7) and be used to quantify the amount of water in the fuel cell.

For example, for dry gas supply $\left(F_{\mathrm{w}}^{\mathrm{in}}=0\right)$ and no water partition $\left(\alpha_{\mathrm{W}}=0\right)$, partial water balance Equation (7) becomes $F_{\mathrm{w}}^{\text {out }}=F_{\text {prod }}$. It gives the relative humidity in the cathode compartment, according to Fig. 5. The correct relative humidity $(\Phi)$ is between $80 \%$ and $100 \%$. It can be noticed that extra humidification is essential when relative humidity is less than $80 \%$, which occurs at high temperatures and high air stoichiometry. The influence of air stoichiometry at a constant temperature is also noticeable.

Being able to estimate the relative humidity, the experiments can be classified according to quantified degrees of flooding and drying. To combine the operating parameters, the use of fault trees [53,54] should be a relevant solution.

Once the reference database is achieved, it has to be separated into two parts: one to be used for the diagnostic tool development and the other to test the diagnostic tool. Representativeness of faults is important for the part of the database used for development of the tool. The part used for tests has to be relevant enough to allow for the evaluation of the performances of the diagnostic tool.

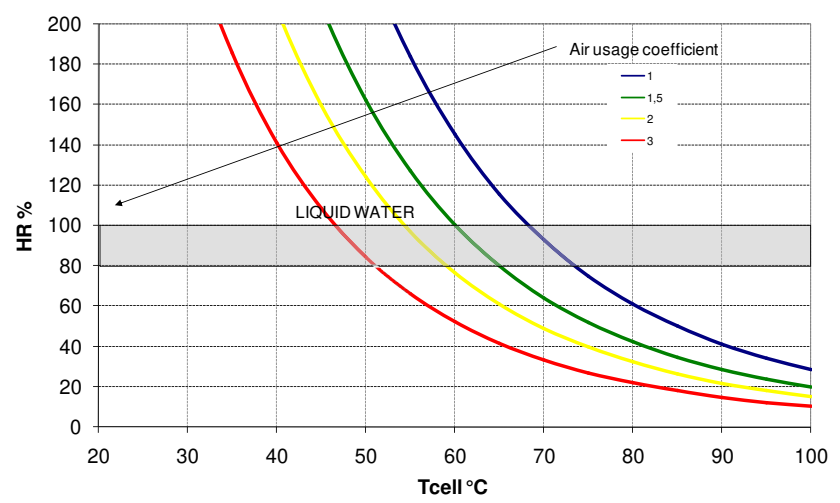

Fig. 5 - Relative humidity at the cathode depending on the operating temperature and the overstoichiometry coefficient $(\lambda)$. 


\section{Classification and result performances}

To identify the various steps from measurements to final diagnosis use, the diagnostic stages are summarised in Fig. 6: (i) feature selection and extraction; (ii) fault detection, which includes model-based or signal-based approaches; (iii) classification: the faults to be detected are gathered into classes with specific algorithms; (iv) results validation: evaluation of the accuracy of diagnostic results and (vi) results interpretation, which aims to verify that diagnosis is meaningful and useful, such as for alarm, prognostic or integration in faulttolerant control.

In data treatment and fault detection methods, the delicate points to eventually take into account are the computation time and the size of the database required. Comparative studies of various approaches have already been assessed in the literature $[33,34]$ and are not considered here. Classification and diagnosis validation will now be discussed.

\section{Determination of defect classes}

Classification consists of clustering the data into classes that share the same default. The classes are usually defined by an expert. For fuel cell diagnosis, "flooding" and "drying" represent two classes corresponding to the same phenomenon (the amount of water). Other defaults may be detected: COdegradation or poisoning has sometimes been included

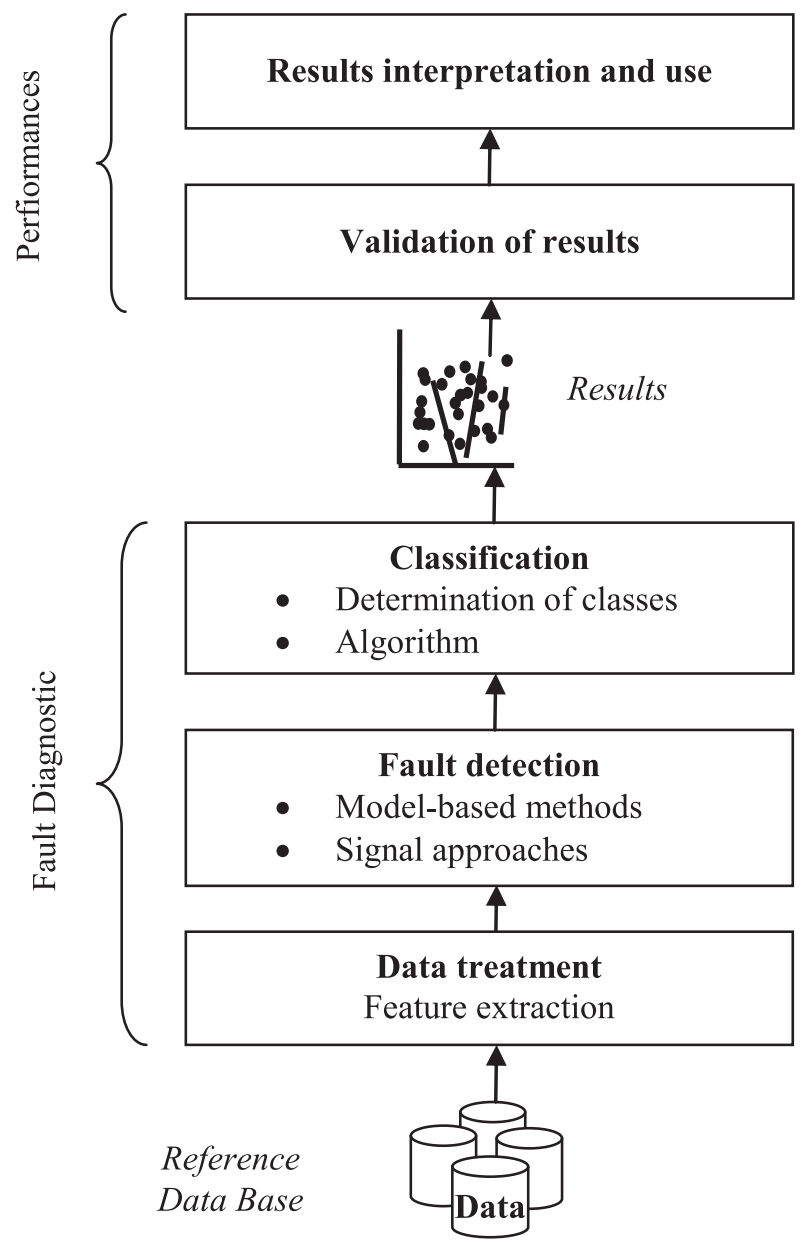

Fig. 6 - Steps of the diagnostic process.
$[5,16,24]$. Most often, only three classes are used: "normal", "flooding" and "drying" [8]. However, S. Wasterlain [38] retained 5 classes: moderated drying, minor drying, light flooding, minor flooding and moderated flooding. Furthermore [21], distinguished the anode from the cathode [25], the amount of water in the membrane and in the electrodes.

Because the effects of flooding and the drying out of the stack are continuous in nature, the frontiers and the number of the classes are arbitrarily chosen. Some algorithms (Kmeans for example) are, however, able to define and move the frontiers. However, the number and limits of the classes will give the final interpretation of the diagnostic system delivered to the user. Interest lies in detecting the default early enough to assess the State of Health, predicting its Remaining Useful Life or deciding on control actions. The link has not been established yet, and disposing of quantitative degrees of defaults as proposed in the previous section would considerably simplify this task.

\section{Classification algorithms}

Classification, or clustering, is a method of data analysis where algorithms are used to gather the new data into classes. A multitude of methods are proposed in the literature and may be viewed from different perspectives. Two viewpoints are presented here: one based on fundamental theoretical concepts and the other on the method to form classes.

The theory and fundamental concepts on which classification is based are [55]:

- Statistical analysis. The similarity between measures are used to partition data $[16,26,36,38]$.

- Fuzzy techniques. The features of the database can be classified to more than one class. This type of algorithms handles the uncertainty of real data $[18,43]$.

- Crisp considers non-overlapping partitions, meaning that a feature either belongs to a class or not. Most of the classification algorithms result in crisp classes. Note that usually fault detection methods, based on residues determination, are of the crisp classification type.

- Neural Networks (NN). Neural networks have input and output nodes. The input layer (input nodes) has a node for each attribute of the feature, each one connected to every output node (output layer). Each connection is associated with a weight, which determines the position of the corresponding output node. Thus, according to an algorithm, which changes the weight's property, output nodes move to form classes $[6,27]$.

Methods of classification may also be presented by the algorithms to form classes:

- Partitional classification, which attempts to directly decompose the dataset into a set of disjoint classes. Some algorithms attempt to determine an integer number of partitions that optimise a certain criterion function. The optimisation of the criterion function is an iterative procedure. K-means belong to this type [55].

- Hierarchical classification, which proceeds successively by either merging smaller classes into larger ones, or by splitting larger classes. The result of the algorithm is a tree 
of classes, called a dendrogram, which shows how the classes are related. By cutting the dendrogram at a desired level, a classification of the data items into disjoint groups is obtained $[54,56]$.

- Density-based classification. The key idea is to group neighbouring features of a dataset into classes based on density conditions.

To evaluate the differences between these methods, Table 2 provides a comparison for some classical methods of these algorithms with 3 criteria. Complexity has to be understood in relation with the database: the processing time of the K-means method proportionally increases with the size of the base, while for the other methods, the processing time increases far more compared with the amount of data. The input parameters are different for each method. Finally, the results are different according to each method.

The choice of the algorithm may require complementary assumptions or expertise. In the context of an online application, the computation time associated with the algorithm is also an important factor. Determining the contribution of a classification algorithm is a problem in itself. Here, we see that evaluating the differences between algorithms is a complex task.

Validation of results

Validation of the results obtained by classification algorithms is a final and necessary step that evaluates the diagnostic performances. Until relatively recently, scant attention had been paid to validation of the results obtained by classification algorithms, which is now an active research area [57].

Validation of the results falls broadly into three classes [58]:

- External validation. The quality of the algorithm is evaluated by comparing the resulting classes with those known from the test database (the true classes). It determines the quality of the algorithm in regard to recognising existing groups.

- Relative validation is based on the evaluation of the consistency of the algorithms, comparing the classes obtained by the same algorithm under different conditions. It determines the quality of the algorithm to generate meaningful groups. It does not include additional information,

\begin{tabular}{lcll}
$\begin{array}{l}\text { Table 2 - Characteristics of classification algorithms from } \\
\text { Ref. [55]. } \\
\text { Method }\end{array}$ & Complexity $^{\mathrm{a}}$ & \multicolumn{1}{c}{$\begin{array}{c}\text { Input } \\
\text { parameters }\end{array}$} & \multicolumn{1}{c}{ Results } \\
\hline $\begin{array}{l}\text { K-means } \\
\text { (partitional) }\end{array}$ & $\mathrm{O}(n)$ & $\begin{array}{l}\text { Number of } \\
\text { classes } \\
\text { Classes radius, } \\
\text { minimum } \\
\text { (density-based) }\end{array}$ & $\begin{array}{l}\text { Centre of } \\
\text { classes } \\
\text { number of } \\
\text { data values to } \\
\text { features } \\
\text { classes }\end{array}$ \\
Classes radius & $\mathrm{O}(n \log n)$ & $\begin{array}{l}\text { Assignment of } \\
\text { data values to } \\
\text { classes }\end{array}$ \\
\hline
\end{tabular}

${ }^{a} n$ is the number of points in the dataset.
- Internal validation consists of calculating properties of the resulting classes, such as compactness, separation and roundness. This family of techniques is based on the assumption that the algorithms should search for classes whose members are close to each other and far from members of other classes. It determines the quality of the algorithm in regard to generating an interesting partition. Internal validation does not require additional information about the data or repetition of the clustering process.

If the test database has been performed correctly, external validation is the best choice. Fault diagnostic results can be easily summarised and classified by building the confusion or contingency matrix [59]. Table 3 shows the confusion matrix: columns represent occurring faults and rows represent diagnosed faults. Therefore, for a fault $f$ : "a" is the number of samples assigned to a fault, " $b$ " represents those samples mistakenly diagnosed as fault $f$, "c" are all samples that were not correctly diagnosed as fault $f$, and " $d$ " evaluates whether the remaining states are properly not diagnosed as fault $f$, which guarantees the overall fault diagnostic performance.

Therefore, the following equations are proposed for directly evaluating the classification performance indexes from the confusion matrix.

Precision for fault $f$ can be defined as the ratio of correct detection to all diagnosed faults

$\operatorname{Prec}(f)=\frac{a}{a+b}$

Recall for fault $f$ can be defined as the ratio of the diagnosed faults to all of the actually occurring faults

$\operatorname{Rec}(f)=\frac{a}{a+c}$

The F1 index (widely used in the machine learning area) combines both precision and recall and is used for evaluating the general performance of the diagnostic method:

$\mathrm{F} 1=\frac{2 \times \operatorname{Prec}(f) \times \operatorname{Rec}(f)}{\operatorname{Prec}(f)+\operatorname{Rec}(f)}$

Accuracy, error and global indexes are complementary indexes to globally evaluate the system classification general performance. Accuracy represents the percentage of correct assignments, not only the correctly diagnosed but also the correctly not occurring and not diagnosed samples. Between several indices, accuracy is the best replacement for the error rate: it can be computed quickly and the deviation is small for more than two classes [58]. Error is the percentage of wrong assignments and is the accuracy supplementary measure. They are formally defined as follows:

$\operatorname{Acc}(f)=\frac{a+d}{a+b+c+d}$

Table 3 - Confusion or contingency matrix [59].

\begin{tabular}{lcc}
\hline $\begin{array}{l}\text { Diagnosed fault } \\
\text { (predicted class) }\end{array}$ & Happening fault (true class) \\
\cline { 2 - 3 } & Yes & No \\
\hline Yes & $\mathrm{a}$ & $\mathrm{b}$ \\
No & $\mathrm{c}$ & $\mathrm{d}$ \\
\hline
\end{tabular}


$\operatorname{Error}(f)=\frac{b+c}{a+b+c+d}=1-\operatorname{Acc}(f)$

If the true classes from the database are not known, or are in addition to the above proposed approach, a "silhouette" index can be determined, which, according to [57], appears to be efficient. A silhouette is the average, over all classes, of the silhouette width of their points [58]. If $x$ is a point in the class $C_{k}$ and $n_{k}$ is the number of points in $C_{k}$, then the silhouette width of $x$ is defined by the ratio:

$S(x)=\frac{b(x)-a(x)}{\max [b(x), a(x)]}$

where $a(x)$ is the average distance between $x$ and all other points in $C_{k}$,

$a(x)=\frac{1}{n_{k}-1} \sum_{y \in C_{k}, y \neq x} d(x, y)$

and $b(x)$ is the minimum of the average distances between $x$ and the points in the other classes,

$b(x)=\min _{h=1 \ldots K, h \neq k}\left[\frac{1}{n_{h}} \sum_{y \in C_{k}} d(x, y)\right]$

For a given point, $x$, the silhouette width ranges from -1 to 1 . If the value is close to -1 , the point is closer, on average, to another class than the one to which it belongs. If the value is close to 1, its average distance to its own class is significantly smaller than to any other class. The higher the silhouette is, the more compact and separated the classes are. A silhouette has already been applied for fault diagnosis of fuel cells [61].

\section{Implementation aspects}

After having developed a fault diagnostic tool and evaluated its performances on a relevant database, the last step is to implement it. Thus, economic viability of the diagnostic tool should now be considered. Three aspects will be discussed: time consumption, energy consumption and diagnostic equipment investment costs. All of these points may potentially lead to modifying a diagnostic method or to preferring one over the other.

\section{Time-consuming aspects}

Time consumption comes both from measurement and algorithm computation time. During these periods of time, the stack is operating for the diagnostic tool and is unavailable for the user. This may be an important point depending on the application, such as with transportation applications.

Measurements for methods using an excitation signal, such as EIS, are taken in two time periods:

- A stabilisation period, which ensures the stability of the operating point for each current density applied to the system. This may take a few seconds, but may be longer because of the thermal time constant. In laboratory tests, this period often lasts 20 or $30 \mathrm{~min}$,

- The measurement duration, which may be long for low frequencies.
The stabilisation period is a very important obstacle for online diagnosis. Furthermore, stabilisation of the stack may take considerable time, for example, in the event of severe flooding or drying.

\section{Energy consumption}

Energy aspects are directly linked to measurements and may also be considered. Estimating the energy consumption $(E)$ of the stack during measurements for diagnostic purposes is straightforward:

$E=\int_{0}^{T} U(t) I(t) d t$

where $U$ is the instantaneous stack voltage, I the instantaneous stack current and $T$ the acquisition time.

Diagnostic tools also need additional equipment for the fuel cell system. Thus, the system's energy consumption may also be estimated and added to the previous calculations.

\section{Material aspects}

Developing a diagnostic methodology involves adding material dedicated to the diagnostic tool to the fuel cell system, which is called the diagnostic system. For example, specific sensors, devices for data acquisition and even a device providing the solicitation signal may be needed. Fig. 7 shows the experimental setup needed for the EIS curves of Fig. 2 [4]. To apply a small amplitude of alternative voltage, the fuel cell has to be excited by a current provided by an AC signal generator. Thus, the electronic load voltage, regulated in current, is treated by a frequency analyser. A software license may also be added (i.e., Labview, dSPACE or Matlab real time). In such a configuration, the cost is important (more than U.S. \$ 28,000 or $20 \mathrm{k} €$ ).

In the case of diagnosis during maintenance phases, this material cost may be acceptable. However, the laboratory material may not be appropriate for real applications. For example, impedance spectrometers are generally limited in voltage and current, which does not enable their use for vehicle or stationary applications during normal operation. Thus, some technological solutions must be found.

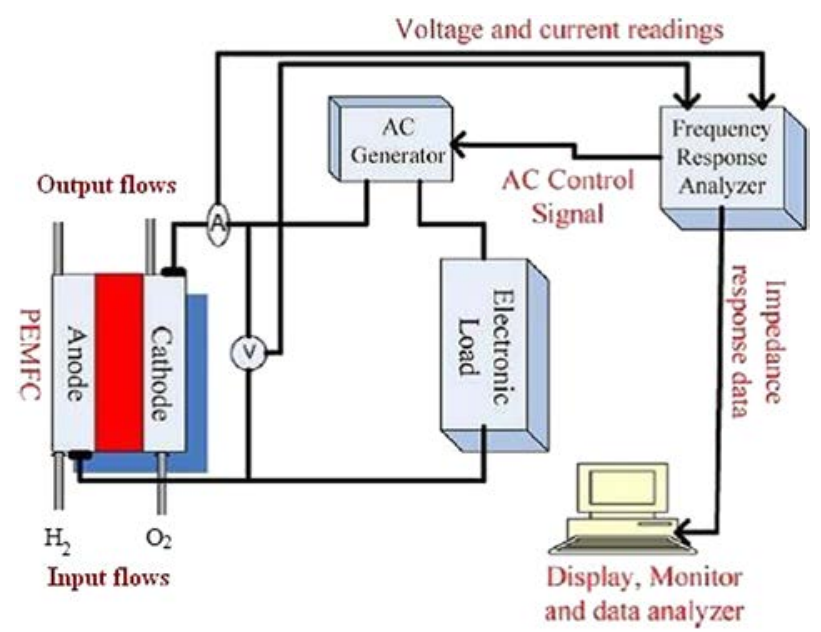

Fig. 7 - Schematic of the experimental setup for EIS, adapted from Ref. [4]. 
Table 4 - Range of the operating parameters.

\begin{tabular}{clllllll} 
Parameter & \multicolumn{1}{c}{$x$} & $\begin{array}{c}j \\
\mathrm{~A} / \mathrm{cm}^{2}\end{array}$ & & & & & \\
& & 0 & 60 & 1.2 & 1.5 & 25 \\
\hline Theoretical range given & $x_{\min }$ & 1 & 90 & 3 & 3 & 75 \\
by the manufacturer & $x_{\max }$ & 0.5 & 80 & 1.3 & 2 & 50 \\
Experimental reference & $x_{\text {ref }}$ & 0 & 60 & 1.8 & 2 & 35 \\
Experimental range & $x_{\min , \operatorname{Exp}}$ & 0 & 0.7 & 80 & 3 & 3 & 75 \\
& $x_{\max , \operatorname{Exp}}$ & & & & &
\end{tabular}

Considering mass production, the global cost has to decrease dramatically. The cost to produce a fuel cell for automotive industrial production is currently estimated at U.S. \$ 4110 ( $€ 3080$ ) for an $80 \mathrm{~kW}$ fuel cell [46]. In the overall price, the embedded control system is estimated at U.S. \$ 300/ $225 €$, or $7.3 \%$ of the total cost. It would therefore be interesting to estimate the additional cost due to the embedded diagnostic system, which has to be reasonable. Thus, solutions to adapt the material for mass production have to be found and this is a true area of research.

\section{Results and discussion}

To illustrate the proposed guidelines, the results of a diagnostic study [38] are now considered. This diagnostic tool has been developed on the basis of Electrochemical Impedance Spectroscopy (EIS). To analyse the experimental data collected through Electrochemical Impedance Spectroscopy (EIS) and diagnose the fuel cell stack behaviour, a probabilistic method (Bayesian Networks) has been used. Polarisation curves have been investigated to classify the operating modes. Lastly, a novel architecture of impedance spectrometer has been developed for large fuel cell stacks that need high-voltage [62]. Various tests have been performed on different fuel cell stacks operated under normal and degrading conditions according to an appropriate experimental design.

\subsection{Experimental means}

The studied stack is a 20-cell $100 \mathrm{~cm}^{2}$ active area fuel cell stack. The stack was assembled with commercial perfluorosulfonic Membrane-Electrodes Assemblies (MEA) graphite bipolar plates and electrodes with $100 \mathrm{~cm}^{2}$ areas. The experiments and EIS measurements have been performed using a $10 \mathrm{~kW}$ test bench developed in-lab.

The operating parameters (current density $j$, stack temperature $\mathrm{T}$, anode overstoichiometry $\lambda_{\mathrm{a}}$, cathode overstoichiometry $\lambda_{\mathrm{c}}$, relative humidity $\Phi$ ) and their ranges, given by the manufacturer and used for experimentation, are shown in Table 4. The experimentally generated operating conditions were created using a 2-level-fractional experimental design. To prevent the measurements from suffering the influence of past events on the fuel cell state, the test protocol provides a stabilisation time of $30 \mathrm{~min}$ after each change of operating parameters.

The result of the experimental design is that 11 operating conditions have been retained, and 5 classes have been chosen: moderated drying (2 operating conditions), minor drying (3 operating conditions), light flooding (1 operating condition), minor flooding (2 operating conditions) and moderated flooding (2 operating conditions), for a current density of $0.5 \mathrm{~A} /$ $\mathrm{cm}^{2}$. The global reference database used for algorithm learning and testing is composed of 231 impedance spectra. For the Bayesian approach, the database size has an important impact on the correct and incorrect fault detections. To obtain an accurate classification with a Bayesian networks approach, the learning database represents $75 \%$ of the experimental database, and thus approximately $25 \%$ is left for the tests $(62$ impedance spectroscopy spectra).

To achieve the impedance spectroscopy spectra and to limit the size of the database, only one frequency per decade has been used: $5 \mathrm{kHz}, 500 \mathrm{~Hz}, 50 \mathrm{~Hz}, 5 \mathrm{~Hz}, 775 \mathrm{mHz}$ and $50 \mathrm{mHz}$.

The test database is made of 68 impedance spectroscopy spectra:

- 10 experimental impedance spectroscopy spectra of moderated drying (f1)

- 27 experimental impedance spectroscopy spectra of minor drying (f2)

- 5 experimental impedance spectroscopy spectra of light flooding (f3)

- 10 experimental impedance spectroscopy spectra of minor flooding (f4)

- 10 experimental impedance spectroscopy spectra of moderated flooding (f5)

The normal state of the fuel cell has 6 impedance spectroscopy spectra.

\section{Database}

The operating parameters that have been used to establish Wasterlain's test database are presented in Table 5. Because the pressure does not vary in these experiments, it has not been taken into account. The reference point has been chosen close to the proposed manufacturer nominal point. The experimental range is smaller than the range given by the manufacturer to avoid instability. Below these ranges,

Table 5 - Relative variations of experimental measurements.

\begin{tabular}{lccccc}
\hline Operating parameter & $x$ & $j \mathrm{~A} / \mathrm{cm}^{2}$ & $\mathrm{~T},{ }^{\circ} \mathrm{C}$ & $\lambda_{\mathrm{a}}$ & \multicolumn{1}{c}{$\lambda_{\mathrm{c}}$} \\
\hline Relatives variations & $\left.\frac{\Delta x}{\mathrm{x}}\right|_{\text {min,Exp }}$ & $-100 \%$ & $-25 \%$ & $+38 \%$ & 0 \\
& $\left.\frac{\Delta x}{\mathrm{x}}\right|_{\text {max, Exp }}$ & $40 \%$ & 0 & $131 \%$ & $50 \%$ \\
$\begin{array}{l}\text { Experimental/Theoretical } \\
\text { Ratio }\end{array}$ & $\frac{\Delta x_{\mathrm{Exp}}}{\Delta x_{\text {Man }}}$ & $70 \%$ & $67 \%$ & $67 \%$ & $67 \%$ \\
\hline
\end{tabular}


Table 5 presents the relative variations and rate of experimental range. Considering the relative variations with respect to the operating point, only the current density (j) exhibits a significant change around the reference point. The maximal temperature $(T)$ and the minimal cathode overstoichiometry $\left(\lambda_{c}\right)$ are the reference value, to avoid instability due to excessive drying of the stack. The anode overstoichiometry $\left(\lambda_{\mathrm{a}}\right)$ is also always above the referencing point for the same reasons. These results show the difficulty encountered to obtain a database that is sufficiently representative of the practicable range found in real operating conditions. The rate of the experimental range on the theoretical range is an interesting indicator: at least $67 \%$ of the operating range has been used during the tests. Thus, experiments are significantly representative of the operating range of the fuel cell.

Evaluations of the degrees of flooding and drying have been carried out according to Equations (7) and (8). Eleven operating conditions have been considered during the experiments, and, from the nominal operating parameters, the relative humidities have been estimated for the cathode and the anode. For the operating conditions leading to "moderate flooding", the relative humidities of the anode and cathode side exceed $100 \%$ (water condensate). Similarly for the case of "minor drying", relative humidity in the cathode side is lower than $80 \%$. These relative humidities have been estimated using a basic distribution fluid model (partial balance) in a perfectly stirred reactor (Equation (7)) with no water partition $\left(\alpha_{\mathrm{w}}=0\right.$ in Equation (8)). To increase consistency, the partition coefficient could be refined, either from experimental data or from the water transport model.

\section{Classification algorithms}

The indexes proposed in Section 3 can now be calculated from the results on the test database. From the 68 spectra that have been classified, only 1 spectrum, which was belonging to a moderate drying class (f1), has been classified as a moderate flooding class (f5).

The confusion matrix for the moderate drying (f1) is given in Table 6.

Indicators are then:

$\operatorname{Prec}(\mathrm{f} 1)=\frac{9}{9+1}=90 \%$

which means that among all detections of moderated drying, $90 \%$ will be true and $10 \%$ will be false.

$\operatorname{Rec}(\mathrm{f} 1)=\frac{9}{9+0}=100 \%$

This means that all the moderated drying will be detected.

Table 6 - Confusion matrix for fault f1 moderate drying.

\begin{tabular}{lcc}
\hline \multirow{2}{*}{$\begin{array}{l}\text { Diagnosed fault } \\
\text { (predicted class) }\end{array}$} & Happening fault (true class) \\
\cline { 2 - 3 } & Yes & No \\
\hline Yes & 9 & 1 \\
No & 0 & 58 \\
\hline
\end{tabular}

Thus, the F1 index is:

$\mathrm{F} 1=\frac{2 \times \operatorname{Prec}(\mathrm{f} 1) \times \operatorname{Rec}(\mathrm{f} 1)}{\operatorname{Prec}(\mathrm{f} 1)+\operatorname{Rec}(\mathrm{f} 1)}=94.7 \%$

Additionally, accuracy is:

$\operatorname{Acc}(\mathrm{f} 1)=\frac{9+58}{9+1+0+58}=98.5 \%$

This means that $98.5 \%$ of cases are well classified.

Thus, the error is:

$\operatorname{Error}(\mathrm{f} 1)=1-\operatorname{Acc}(\mathrm{f} 1)=1.5 \%$

$1.5 \%$ of cases are not well classified.

Similar tables and indices have been populated for each of the 5 faults. In addition, a table summing all faults has also been evaluated. Table 7 shows the resulting indexes in a single table, as proposed by Ref. [60] for multi-fault detection.

In this way, performance indexes can now be easily evaluated. Table 7 shows complete and detailed information on classification performance. Note that even normal state performance was evaluated in the same manner. Precision gives information about the diagnosed samples, recall gathers the information about the occurring faults, and the F1 index gives a single normalised measurement for the evaluation of the general system performance. Accuracy and error are supplementary measurements about the classification validity of the results.

The global index shows how many samples have been well-diagnosed through all of the existing classes, thereby providing a notably valuable measurement with regard to the system's overall diagnostic correctness. High values in that measurement are difficult to achieve (as they require a perfect diagnosis for each sample) and not only indicate a good performance diagnosing the isolated classes but also ensure a good performance when faced with simultaneous faults. The global index is the lower index simply because it focuses on the totally well-diagnosed samples throughout all of the existing classes that are in this example 5 compared with the original 6.

\section{Implementation aspects}

As the database is representative of the defaults of flooding and drying, and as the performance of the algorithm is good, the viability of the approach has to be investigated. In this section, we propose to compare the polarisation curve and the impedance spectroscopy spectra. Table 8 shows the energy cost of experiments and the corresponding experimental duration. Considering the polarisation curve, an interval of $400 \mathrm{~ms}$ has been marked to stabilise the system between each

Table 7 - Indexes evaluation.

\begin{tabular}{lccccccc}
\hline Index & Normal & f1 & f2 & f3 & f4 & f5 & $\Sigma f$ \\
\hline Prec (\%) & 100 & 90 & 100 & 100 & 100 & 100 & 98.5 \\
Rec (\%) & 100 & 100 & 100 & 100 & 100 & 100 & 100 \\
F1 (\%) & 100 & 94.7 & 100 & 100 & 100 & 100 & 99 \\
Acc (\%) & 100 & 98.5 & 100 & 100 & 100 & 100 & 99.75 \\
Error (\%) & 0 & 1.5 & 0 & 0 & 0 & 0 & 0.25 \\
Global (\%) & $5 / 6=83.3$ & & & & & & \\
\hline
\end{tabular}


Table 8 - Energetic cost of experiments and experimental duration.

Polarisation

Measured curves for EIS $(I=50 \mathrm{~A})$

Total EIS

\begin{tabular}{ccccccccc} 
& & $50 \mathrm{mHz}$ & $775 \mathrm{mHz}$ & $5 \mathrm{~Hz}$ & $50 \mathrm{~Hz}$ & $500 \mathrm{~Hz}$ & $5 \mathrm{KHz}$ \\
\hline Energy (W h) & 156 & 17.5 & 11 & 0.35 & 0.035 & 0.0035 & 0.00035 & 29 \\
Experimental & 1200 & 100 & 64.6 & 2 & 0.2 & 0.02 & 0.002 & 167 \\
duration (s) & & & & & & & & \\
\hline
\end{tabular}

modification of the operating conditions. Thus, $20 \mathrm{~min}$ and $156 \mathrm{~W}$ h are required to obtain the polarisation curve. For the full impedance spectrum, the applied disturbance must be repeated at different frequencies from $50 \mathrm{mHz}$ to $5 \mathrm{kHz}$. Each frequency curve gives one point of the total EIS curve. Time acquisition and required energy are more important when frequency decreases.

The total energy consumed for EIS is approximately 5 times less than for polarisation. Table 8 also highlights that the experimental period needed is shorter (less than $3 \mathrm{~min}$ for EIS and $20 \mathrm{~min}$ for polarisation). To reduce the time measurements needed to acquire the data and to be closer to pseudoreal time measurement, frequency at $50 \mathrm{mHz}$ was dismissed for the Bayesian approach, despite the importance of the real part of the impedance. The EIS method may also be improved to further decrease the experimental period: the frequency range to be measured $(<1 \mathrm{~Hz})$ may be truncated [38], or a signal with an interlaced frequency [49] may be used.

The last step is to compare the equipment investment for both approaches. Table 9 provides a list of the material and the software investment. This table highlights the most important investments, which are about U.S. \$28,000 (20 k€). To decrease this cost, some solutions can be considered, such as replacing the active electronic load with a simple resistance or using the static converter to eliminate the frequency generator. It appears that EIS is a more expensive method than polarisation, and some research topics are currently being investigated to find new solutions to system excitation and spectral analysis. As software has been developed specifically for this application, investment may also include the working time or the cost in the event of commercial acquisition.

It can be noted that this part of the paper may be considered independently from the others. Here, material, energy and time consumption aspects allow for the estimation of the relevance of a diagnostic approach for implementation, once this approach has been properly validated. Tables 8 and 9 are sufficient to show that EIS approaches need to be improved in regard to equipment cost, but have low energy consumption and acquisition times. Conversely, a polarisation approach seems unsuited to an embedded system because the consumption time per curve is very long and test conditions must avoid stack degradation. New diagnostic approaches should be assessed in the same manner.

Table 9 - Components for diagnostic systems.

\begin{tabular}{lll}
\hline Method & \multicolumn{1}{c}{ Polarisation } & \multicolumn{1}{c}{ EIS } \\
\hline Measuring instrument & Electronic load & Electronic load \\
Excitation system & - & AC generator \\
Data acquisition & Standard computer & Spectral analyser \\
Software & Yes & Yes \\
\hline
\end{tabular}

\section{Conclusions}

This work aims to provide tools to enable a comparison of diagnostic approaches for fuel cells. The first section proposed guidelines that are applied to a real diagnosis study in the second section. This paper highlights the crucial importance of the database, not only to build the reference database but also to determine the limits of default classes and validate the diagnostic tool. To quantify the progressive degrees of drying or flooding, simple equations to estimate the relative humidity in the stack under applied operating conditions have been given. The results on the Wasterlains' study are consistent despite the highly debatable strong assumption that the water produced at the cathode remains in the cathode compartment. This approach has to be pursued to refine the partition coefficient, either from experimental data or from the water transport model.

Validation indexes to estimate algorithm performances are notably easy to establish, making other algorithm comparisons unnecessary. This step is important for comparing the different diagnostic approaches, which, however, are valid only if the quality of the reference database is good, which means that the proposed tools are complementary and must be used together.

Finally, implementation aspects present valuable new insights into the diagnostic approaches utilised. Energy and time consumption very clearly show whether the considered approach has to be adapted to better fit the requirements for extensive use. The equipment needed for the diagnostic system is thus far not suitable for mass production.

Though this paper has raised a number of unsolved problems, the proposed tools to establish quantitative criteria of diagnostic evaluations are ready to be used to establish milestones of benchmarking for diagnostic tool comparison.

\section{R E F E R E N C E S}

[1] Ciureanu M, Roberge R. Electrochemical impedance study of PEM fuel cells. Experimental diagnostics and modeling of air cathodes. J Phys Chem B 2001;105:3531-9.

[2] Fouquet, Doulet C, Nouillan C, Dauphin-Tanguy G, OuldBouamama B. Model based PEM fuel cell state-of-health monitoring via ac impedance measurements. J Power Sourc 2006;159:905-13.

[3] Fouquet N. Real time model-based Monitoring of a PEM fuel cell flooding and drying out. In: IEEE vehicle power and propulsion conference (VPPC), Lille, France; 2010. pp. 1-8.

[4] Gebregergis A, Pillay P, Rengaswamy R. PEMFC fault diagnosis, modeling, and mitigation. IEEE Trans Ind Appl 2010;46:295-303. 
[5] Kadyk T, Hanke-Rauschenbach R, Sundmacher K. Nonlinear frequency response analysis of PEM fuel cells for diagnosis of dehydration, flooding and CO-poisoning. J Electroanal Chem 2009;630:19-27.

[6] Kim J, Lee I, Tak Y, Cho BH. State-of-health diagnosis based on hamming neural network using output voltage pattern recognition for a PEM fuel cell. Int J Hydrogen Energy 2012;37:4280-9.

[7] Le Canut JM, Abouatallah RM, Harrington DA. Detection of membrane drying, fuel cell flooding, and anode catalyst poisoning on PEMFC stacks by electrochemical impedance spectroscopy. J Electrochem Soc 2006;153(5):A857-64.

[8] Mérida W, Harrington DA, Le Canut JM, McLean G. Characterization of proton exchange membrane fuel cell (PEMFC) failures via electrochemical impedance spectroscopy. J Power Sourc 2006;161:264-74.

[9] Saleh FS, Easton EB. Diagnosing degradation within PEM fuel cell catalyst layers using electrochemical impedance spectroscopy. J Electrochem Soc 2012;159(5):B546-53.

[10] Wagner N, Gtilzow E. Change of electrochemical impedance spectra (EIS) with time during CO-poisoning of the Pt-anode in a membrane fuel cell. J Power Sourc 2004;127:341-7.

[11] Yuan X, Sun JC, Blanco M, Wang H, Zhang J, Wilkinson DP. AC impedance diagnosis of a $500 \mathrm{~W}$ PEM fuel ceil stack part I: stack impedance. J Power Sourc 2006;161:920-8.

[12] Yuan X, Sun JC, Blanco M, Wang H, Zhang J, Wilkinson DP. AC impedance diagnosis of a $500 \mathrm{~W}$ PEM fuel cell stack part II: individual cell impedance. J Power Sourc 2006;161:929-37.

[13] Aitouche, Yang Q Bouamama BO. Fault detection and isolation of PEM fuel cell system based on nonlinear analytical redundancy. Eur Phys J Appl Phys 2012;54(2):23408-19.

[14] Barbir F, Gorgun H, Wang X. Relationship between pressure drop and cell resistance as a diagnostic tool for PEM fuel cells. J Power Sourc 2005;141:96-101.

[15] Escobet, Feroldi D, de Lira S, Puig V, Quevedo J, Riera J, et al. Model-based fault diagnosis in PEM fuel cell systems. J Power Sourc 2009;192:216-23.

[16] Hernandez A, Hissel D, Outbib R. Fuel cell fault diagnosis: a stochastic approach. In: IEEE ISIE 2006, Montreal, Quebec, Canada; 2006, July 9-12.

[17] Hernandez A, Hissel D, Outbib R. Modeling and fault diagnosis of a polymer electrolyte fuel cell using electrical equivalent analysis. IEEE Trans Energy Convers 2010;25:148-60.

[18] Hissel D, Péra MC, Kauffmann JM. Diagnosis of automotive fuel cell power generators. J Power Sourc 2004;128:239-46.

[19] Jung M, Ashford MD, Williams KA. Analysis of a fuel cell system by a step response. Fuel Cell 2011;11(2):327-38.

[20] Niroumand AM, Mérida W, Eikerling M, Saif M. Pressure-voltage oscillations as a diagnostic tool for PEFC cathodes. Electrochem Commun 2010;12:122-4.

[21] Niroumand AM, Mérida W, Saif M. PEM fuel cell low flow FDI. J Process Contr 2011;21:602-12.

[22] Riascos LAM, Simoes MG, Miyagi PE. On-line fault diagnostic system for proton exchange membrane fuel cells. J Power Sourc 2008;175:419-29.

[23] Rubio MA, Urquia A, Dormido S. Diagnosis of PEM fuel cells through current interruption. J Power Sourc 2007;171:670-7.

[24] Rubio MA, Urquia A, Dormido S. Diagnosis of performance degradation phenomena in PEM fuel cells. Int J Hydrogen Energy 2010;35:2586-90.

[25] Stumper J, Löhr M, Hamada S. Diagnostic tools for liquid water in PEM fuel cells. J Power Sourc 2005;143:150-7.

[26] Xuea X, Tanga J, Sammesa N, Ding Y. Model-based condition monitoring of PEM fuel cell using Hotelling 12 control limit. J Power Sourc 2006;162:388-99.
[27] Yousfi Steiner N, Hissel D, Moçotéguy P, Candusso D. Diagnosis of polymer electrolyte fuel cells failure modes (flooding \& drying out) by neural networks modeling. Int J Hydrogen Energy 2011;36:3067-75.

[28] Yousfi Steiner N, Candusso D, Hissel D, Moçotéguy P. Modelbased diagnosis for proton exchange membrane fuel cells. Math Comput Simul 2010;81:158-70.

[29] Chen J, Zhou B. Diagnosis of PEM fuel cell stack dynamic behaviors. J Power Sourc 2008;177:83-95.

[30] Denisov E. PEM fuel cell electrical fluctuations and noises and their diagnosis properties $[\mathrm{PhD}]$. Université de Poitier; December 2011 (in English).

[31] Legros B, Thivel PX, Nogueira RP. First results on PEMFC diagnosis by electrochemical noise. Electrochem Commun 2011;13(12):1514-6.

[32] Yousfi Steiner N, Hissel D, Moçotéguy P, Candusso D. Nonintrusive diagnosis of polymer electrolyte fuel cells by wavelet packet transform. Int J Hydrogen Energy 2011;36:740-6.

[33] Youfi-Steiner N, Moçotéguy Ph, Candusso D, Hissel D, Hernandez A, Aslanides A. A review on PEM voltage degradation associated with water management: impact, influent factors and characterization. J Power Sourc 2008; 183:260-74.

[34] Petrone R, Zheng Z, Hissel D, Péra MC, Pianese C, Sorrentino M, et al. A review on model-based diagnosis methodologies for PEMFCs. Int J Hydrogen Energy 2013;38:7077-91.

[35] Zeller A, Rallières O, Régnier J, Turpin C. Diagnosis of a hydrogen/air fuel cell by a statistical model-based method. In: IEEE vehicle power and propulsion conference (VPPC); 2010. pp. 1-6.

[36] Hua J, Li J, Ouyang M, Lu L, Xu L. Proton exchange membrane fuel cell system diagnosis based on the multivariate statistical method. Int J Hydrogen Energy 2011;36(16):9896-905.

[37] Placca L, Kouta R, Candusso D, Blachot J-F, Charon W. Analysis of PEM fuel cell experimental data using principal component analysis and multi linear regression. Int J Hydrogen Energy 2010;35(10):4582-91.

[38] Wasterlain S, Candusso D, Harel F, François X, Hissel D. Diagnosis of a fuel cell stack using electrochemical impedance spectroscopy and bayesian networks. In: 2010 IEEE vehicle power and propulsion conference (VPPC); 2010. pp. 1-6.

[39] De Lira S, Puig V, Quevedo J, Husar A. LPV observer design for PEM fuel cell system: application to fault detection. J Power Sourc 2011;196:4298-305.

[40] Giurgea S, Tirnovan R, Hissel D, Outbib R. An analysis of fluidic voltage statistical correlation for a diagnosis of PEM fuel cell flooding. Int J Hydrogen Energy 2013;38:4689-96.

[41] Isermann R. Fault-diagnosis systems. Springer; 2006. 465pp.

[42] Cooper KR, Smith M. Electrical test methods for on-line fuel cell ohmic resistance measurement. J Power Sourc 2006;160:1088-95.

[43] Hissel D, Candusso D, Harel F. Fuzzy-clustering durability diagnosis of polymer electrolyte fuel cells dedicated to transportation applications. IEEE Trans Veh Technol 2007;56(5):2414-20.

[44] Onanena R, Oukhellou L, Candusso D, Same A, Hissel D, Aknin P. The estimation of fuel cell operating time for predictive maintenance strategies. Int J Hydrogen Energy 2010;35(15):8022-9.

[45] Onanena R, Oukhellou L, Candusso D, Harel F, Hissel D, Aknin P. Fuel cells static and dynamic characterizations as tools for the estimation of their ageing time. Int J Hydrogen Energy 2011;36:1730-9. 
[46] Marcinkosk J, James BD, Kalinoski JA, Podolski W, Benjamin T, Kopasz J. Manufacturing process assumptions used in fuel cell system cost analyses. J Power Sourc 2011;196:5282-92.

[48] Riascos MA, Pereira DD. Limit operating temperature in PEM fuel cells. J Electrochem Soc 2009;156(9):B1051-8.

[49] Wahdame B, Candusso D, François X, Harel F, Kauffmann JM, Coquery G. Design of experiment techniques for fuel cell characterisation and development. Int J Hydrogen Energy 2009;34:967-80.

[50] Ji M, Wei Z. A review of water management in polymer electrolyte membrane fuel cells. Energies 2009;2:1057-106.

[51] Ous T, Arcoumanis C. Visualisation of water accumulation in the flow channels of PEMFC under various operating conditions. J Power Sourc 2009;187:182-9.

[52] Larminie J, Dicks A. Fuel cell systems explained. 2nd ed. England: John Wiley \& Sons Ltd; 2003.

[53] Placca L, Kouta R. Fault tree analysis for PEM fuel cell degradation process modelling. Int J Hydrogen Energy 2011;36:12393-405.

[54] Yousfi-Steiner N, Hissel D, Moçotéguy P, Candusso D, Marra D, Pianese C, et al. Application of fault tree analysis to fuel cell diagnosis. Fuel Cell 2012;12(2):302-9.

[55] Halkidi M, Batistakis Y, Vazirgiannis M. On clustering validation techniques. J Intell Inf Syst 2001;17(2-3):107-45.
[56] Arsie I, Di Filippi A, Marra D, Pianese C, Sorrentino M. Fault tree analysis aimed to design and implement on-field fault detection and isolation schemes for SOFC systems. In: ASME. 8th International conference on fuel cell science, engineering and technology, vol. 1; 2010. pp. 1-11.

[57] Arbelaitz O, Gurrutxaga I, Muguerza J, Pérez JM, Perona I. An extensive comparative study of cluster validity indices. Pattern Recogn 2013;46:243-56.

[58] Brun M, Sima C, Hua J, Lowey J, Carroll B, Suh E, et al. Modelbased evaluation of clustering validation measures. Pattern Recogn 2007;40:807-24.

[59] Yélamos I, Graells M, Puigjaner L, Escudero G. Simultaneous fault diagnosis in chemical plants using a MultiLabel approach. AIChE J 2007;53(11):2871-84.

[60] Yélamos I, Escudero G, Graells M, Puigjaner L. Performance assessment of a novel fault diagnosis system based on support vector machines. Comput Chem Eng 2009;33:244-55.

[61] Wang K. Algorithmes et méthodes pour le diagnostic exsitu et in-situ de systèmes de Piles à Combustibles à hautes températures de type oxyde-solide, Thèse de Doctorat de l'Université de Franche Comté, $N^{\circ}$ ordre: 2012107; 2012.

[62] Wasterlain S, Harel F, Candusso D, Hissel D, François X. A new high voltage impedance spectrometer for the diagnostic of the fuel cell stacks. J Fuel Cell Sci Technol 2011;8:024502-11. 6. 